\title{
Industry dynamics in practice: Insights from an industry study
}

Received (in revised form): 4th April, 2007

\begin{abstract}
Bruce E. Perrott
is interested in strategic management. He is concerned with how business and marketing strategies are formulated, formalised and managed through to the implementation phase. This interest is pursued through a broad range of activities including research, post graduate education, management development and consulting. Current research interests focus on corporate and knowledge management and marketing strategy in healthcare. Numerous papers and workshops have been presented in recent times to international conferences and academic forums in Australia, Belgium, Canada, Finland, Norway, China, France, Germany, UK and the United States. He is increasingly involved in working with private and public sector management in helping them to develop profitable growth and effective knowledge management strategies. He recently directed two major research projects investigating strategic issues facing the private hospital industry and dimensions of knowledge management practice, and is currently a member of a large research programme investigating self disclose of medical procedures in the public health system.
\end{abstract}

Keywords industry attractiveness, competitive rivalry, industry structure, contracting framework, private hospital industry, health care services

Abstract Some researchers contend that it is only through a deep understanding of the possibilities and nature of routine coordinated activity that whole industries can be properly framed and understood. This paper sets out to examine industry dynamics of the Australian private hospital industry regarding factors that will impact industry members in setting business and marketing strategy for future directions. A strategy framework is used to examine the extent of competitive rivalry, the threat of new entrants, the role of consumers, the role of substitutes and the role of suppliers. In discussion, an assessment is made of the industry's attractiveness, implications of the findings for industry managers and an overview of future issues facing the industry. Journal of Database Marketing \& Customer Strategy Management (2007) 14, 236-253. doi:10.1057/palgrave.dbm.3250051

Bruce E Perrott UTS

PO Box 123 Broadway, NSW Sydney, Australia Tel: +61 29514 3524; Fax: +61 295143535 ; E-mail: Bruce.perrott@uts. edu.au

\section{INTRODUCTION}

It has been suggested that effective strategic planning in organisations should begin with an analysis of the external environment. ${ }^{1}$ Strategy can then be formulated in the context of the environment in which it operates. One of the aims of strategy goes to the core of the marketing philosophy, which is to create value for key stakeholders. $^{2}$

This paper sets out to examine industry dynamics of the Australian private hospital industry regarding factors that will impact industry members in setting business and marketing strategy for future directions.

Data for this paper have been generated from an industry-funded research project. The research is a two-phased project. This is the first stage of a project designed to better understand the dynamics of the private hospital industry in Australia. This stage will use a framework to analyse the main forces at play in the industry. It will attempt to make an objective assessment of the operating environment for industry members. Data for this first stage will be taken mainly from a range of secondary sources. 


\section{INDUSTRY BACKGROUND}

The underlying driver of the demand for health services will be the ageing Australian population. With a current median age of about 35 years (a 14 per cent rise over the past 15 years), it is expected to rise by another 14 per cent to a median age of 40 years by 2016 . At this inflection point, the utilisation of healthcare services is suggested to rise dramatically, increasing its rate of growth with each subsequent year of age. ${ }^{3}$ This trend provides a strong basis for the projected growth and development of private health services. Added to this population trend is the community expectation for more comprehensive and ongoing health services. Rapid improvements in medical procedures and the underlying technologies reduce risk and post-intervention disability. ${ }^{4}$

The Australian healthcare system has been described as having the distinguishing characteristic of being a mixed economy comprising a tapestry of programmes funded by federal and state government, private health insurance, government-owned institutions, private medical practice, private for-profit and not-for-profit institutions, corner shop pharmacies and large publicly listed and private corporations. ${ }^{5}$
This review will focus on healthcare delivered in Australian private or nonpublic hospitals. There were 532 private hospitals in operation during 2004-2005. The number of available beds was 26,424 with total patient separations of 2.8 million. About four in ten hospital patients were admitted to private hospitals in 2004-2005. Equivalent full-time staff at private hospitals was 48,544 . Patient separations covered by private hospital insurance amounted to 78 per cent. Total income generated at these hospitals totalled AUDS $\$ 6,624$ million. Net operating margin for acute and psychiatric hospitals was 7 per cent, a contrast to the 19 per cent realised for free-standing day hospital facilities. ${ }^{6}$

\section{CONTRACTING FRAMEWORK}

An important aspect of understanding the operating environment of the private health industry is to know the operating framework of the key players participating in the delivery and payment system of private health services. Some researchers contend that it is only through a deep understanding of the possibilities and nature of routine coordinated activity, that whole industries can be properly framed and understood. ${ }^{7}$ Figure 1 outlines the key

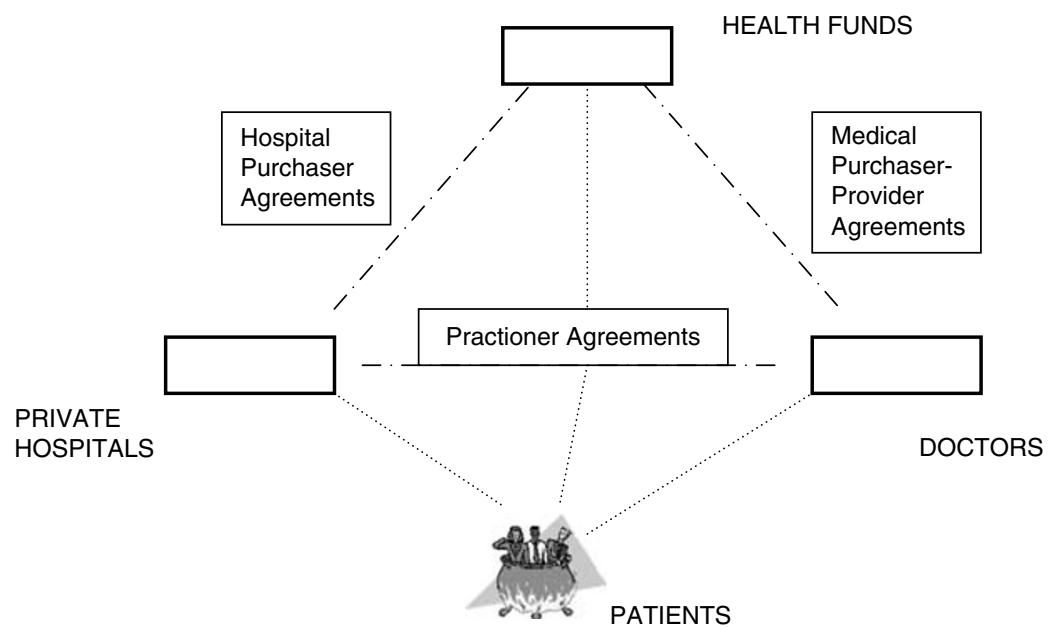

Figure 1: Contracting framework of private health services 
players and the agreements framework existing between them. Marketing of health services in the private sector also needs to be considered in terms of the relationship and agreements that exist between the health funds, doctors and the private hospital groups.

\section{The health fund-private hospital dimension}

Given that the bulk of private hospital revenue comes from treating insured patients, negotiations between a hospital and the health insurance funds can have a crucial bearing on a hospital or health provider's financial performance and its ongoing viability. Negotiations between the two determine the rate a private hospital receives for various services provided to health fund members. ${ }^{8}$ It has been observed that the health funds can be ruthless in these negotiations. ${ }^{9}$

Until the mid-1990s, private hospitals typically set their charges on a cost plus basis with the funds automatically passing on cost increases to members by way of higher premiums. In the second half of the 1990s, as fund membership declined and premiums increased, the health funds became more proactive in negotiating rates with private hospital groups. A new legislative contracting framework introduced in 1995 reinforced the approach.

\section{The private hospital-doctor dimension}

The relationship between private hospitals and doctors is fundamental to service delivery and the operation of all private hospitals. It also has an important impact on the viability of the private hospital business even to the extent of providing some with a decisive competitive advantage. ${ }^{10}$

- Doctors determine the type and extent of services to be administered.
- Doctors often determine where the service will be delivered.

- Doctors are involved in the actual delivery or supervision of the services delivered.

Agreements between private hospitals and doctors often cover conditions of supply and use of premises and medical equipment. These agreements tend to be medium to long term and are referred to as Practitioner Agreements, which enables hospitals to receive payments under Hospital Provider Agreements for services provided by doctors to patients. The nature of agreements made will reflect the negotiating power of both parties. For example, particular hospitals may be located near critical patient supply markets such as large public hospitals and dense population centres. Some doctors may be dominant in the supply of key medical services and hence be critical in designing of a hospital's case mix and/or patient appeal.

\section{The health fund-doctor dimension}

Contracts between Health Funds and doctors are generally outside the influence of Private hospitals. Doctors may play a key role in the dynamics of health fund economics as they usually specify the type and frequency of the services to be delivered, also deciding on the length of stay in a hospital's facilities. A 1997 survey indicated that doctors determined the institution used to deliver health services for 64 per cent of admissions. ${ }^{11}$ Doctors' influence effectively controls the level of payout to privately insured patients.

There has been a resistance by doctors in Australia to contract with the health funds. One report cited that there were only 53 agreements in place as on February 1999. ${ }^{12}$ The Amendment Act 1995 provides for contracts to be made between health funds and providers and are known as Medical Practitioner Providers Agreements (MPAAs). 


\section{Legislative framework for health services}

The States and Territory governments are responsible for licensing and approving private hospitals and day care facilities under the Health Insurance Act of 1973 and the National Health Act 1953, which requires a hospital to be declared by the Commonwealth in order to receive health insurance benefits.

\section{INDUSTRY DYNAMICS}

In order to understand the context of the private hospitals industry, it is useful to undertake an analysis of the key forces and dynamics at a point in time. One framework that can be used to structure this process is the five forces model (after Porter, 1980) ${ }^{13}$ summarised in Figure 2. This has been seen as being one of the most significant contributions to the understanding of industry dynamics and market power through its structureconduct-performance framework. ${ }^{14,15}$

Here, the competitive landscape is at the central point of focus, which examines the nature and details of how the key firms compete in the industry. Potential entrants and likelihood of entry to and exit from the industry are shown at the top of the diagram. The role and threat of substitute products and service are considered at the base of the figure. The impact and bargaining power of buyers is positioned at the right side of the chart. The impact and bargaining power of suppliers to the industry is positioned at the left side of the chart. This paper will use the five forces framework as the basis for review and discussion of the Australian private hospital industry.

\section{Competitive rivalry and industry growth}

This section will examine the competitive landscape of the industry as the central point of focus. It reviews the nature and details of how the key firms compete.

Key changes to industry structure in recent times have occurred mainly in the for-profit sector. For example, the Ramsay acquisition of the Benchmark group of hospitals on May 2004. In addition to increasing the number of private beds by

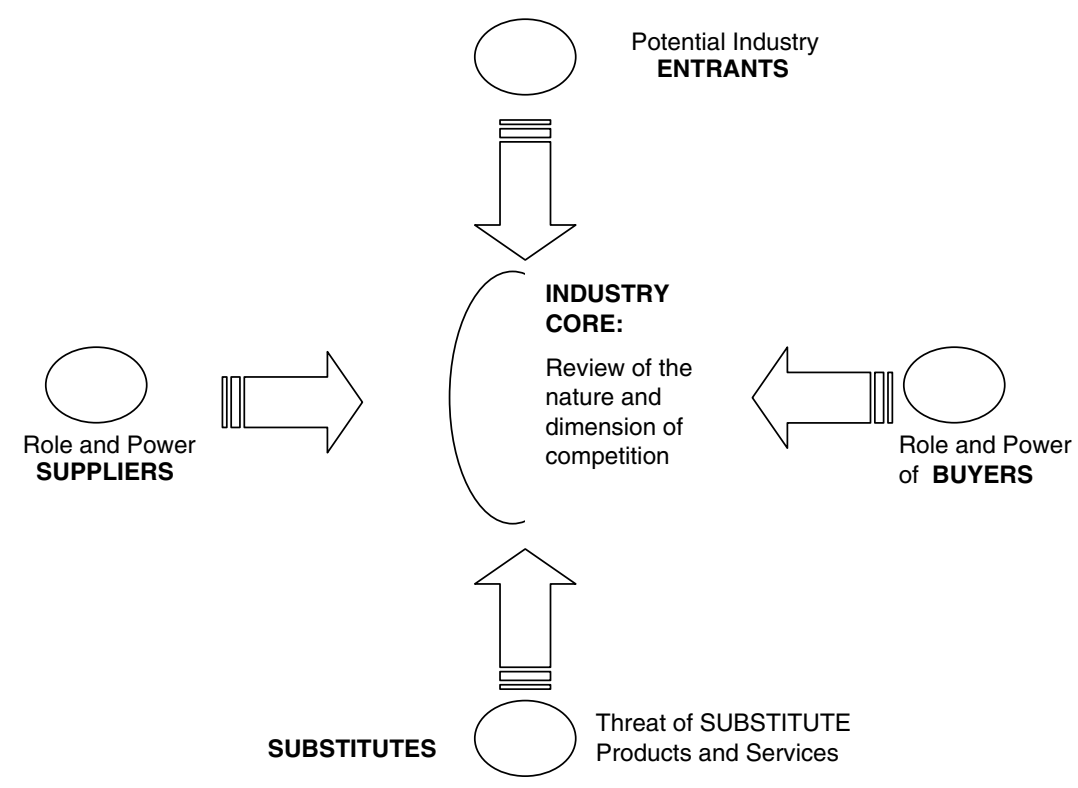

Figure 2: Australian private hospital industry dynamics framework (psychiatric and acute care) 


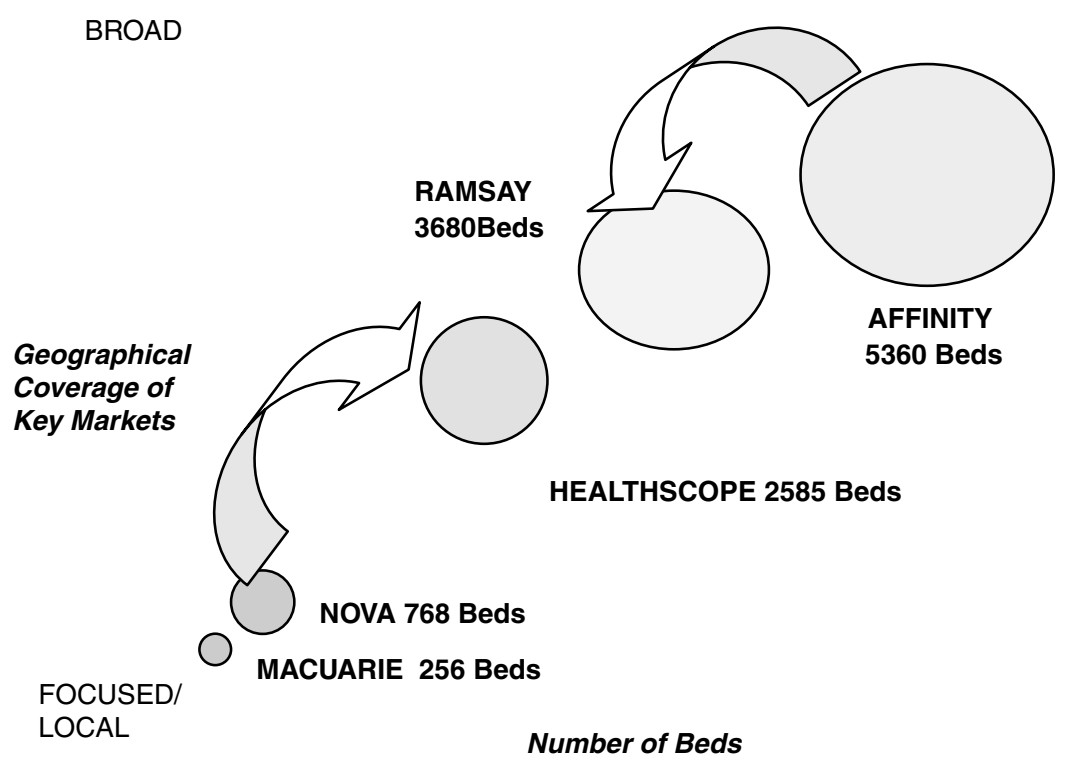

Figure 3: Relative positioning of private hospital companies; For-profit, listed companies (psychiatric and acute care)

34 per cent, the Benchmark acquisition also strengthened Ramsay's geographical market coverage with the addition of ten hospitals in Victoria and South Australia where Ramsay was previously under represented.

Market shares of beds in the for-profit sector in 2003 were estimated as follows ${ }^{16}$ :

$\begin{array}{lrr}\text { Affinity } & 5,360 \text { beds } & 42.4 \% \text { share } \\ \text { Ramsay } & 3,680 \text { beds } & 29.1 \% \text { share } \\ \text { Healthscope } & 2,585 \text { beds } & 20.4 \% \text { share } \\ \text { Nova Health } & 768 \text { beds } & 6.1 \% \text { share } \\ \text { Macquarie Health } & 256 \text { beds } & 2.0 \% \text { share }\end{array}$

The competitive landscape continued to change during 2004 and 2005 with further consolidation from acquisition and merger. The most significant of these was in April 2005 when the Ramsay Group acquired Affinity, their largest competitor. The acquisition cost was AUD $\$ 1,428$ million. Before approving this merger, Australia's competition watchdog, the ACCC, required Ramsay to divest 14 of the acquired hospitals, post acquisition. ${ }^{17}$ In 2005 Healthscope acquired the Nova group, adding further to the industry's consolidation. The merging landscape of the for-profit sector is shown in Figure 3.

A more recent summary of private hospital bed share in the for-profit sector has been estimated as follows:
Ramsay
9,334
Healthscope
3,353

Competitive intensity between competing hospitals is modified due to the unique geographical positioning of each company's hospitals that are located strategically near the markets which yield both patients and medical referrals.

It has been observed that: 'Few private hospitals in major Australian cities could consider themselves to have a dominant market position - most treatments are available in several private and public hospitals' ${ }^{18}$ Hence private hospital companies do not intensely compete on price or the type of service offered. This geographical positioning also substantially reduces the need to aggressively differentiate with product, service and brand strategies. It also has an impact by way of containing 
the level of competitive marketing expenditure necessary to maintain the desired level of bed occupancy in specific locations.

To the degree that these companies compete, there are a number of elements that need to be considered: ${ }^{19}$

- The type and reputation of referring doctors (General Practitioners and Specialists).

- Geographical location of the hospital facility.

- Product/case mix offered.

- Availability of quality staff.

Industry growth rate is also a factor that can impact on the degree of competitive rivalry existing in an industry at a point in time. For example if the rate of growth is slow, it could be expected that competition would intensify as the key players fight for their share of the available growth. ${ }^{20}$ Growth rate will also have an impact on the level of attractiveness to potential new entrants to the industry.

The number of private acute and psychiatric hospitals in operation in Australia decreased by five during 2002-2003 to 296. The average number of available beds in this segment was 24,454 , a decrease of 1 per cent from the previous year. The average number of beds available per hospital increased from 82 in 2001-2002 to 83 in 2002-2003. Almost 74 per cent of available beds in these hospitals during 2002-2003 were in hospitals within the ABS Capital City Statistical Divisions where 64 per cent of Australia's population lived. ${ }^{21}$

An important measure of operating efficiency is bed occupancy. In 2002-2003, this segment had an occupancy rate of 75.6 per cent, which was marginally higher than the previous year with 75.2 per cent. It is also significant to note that the occupancy rate was higher in hospitals located in the Capital City Statistical Divisions at 77.3 per cent, compared with 70.9 per cent in Rest of State and Territory Divisions. ${ }^{21}$ Hence private hospital bed assets near urban populations will be highly valued in terms of market positioning and yield potential. It will also be a strong competitive advantage for companies with hospitals with established operations, which have established networks of referring doctors.

Another measure of industry growth is recognised as patient separations (ie patient stays in hospital). There was only a marginal increase of 1 per cent in patient separations in 2002-2003 to 2.1 million for private acute and psychiatric hospitals. Increases over the two previous years were 7 and 9 per cent, respectively. The average annual growth rate for the last five years is reported to be 6 per cent. ${ }^{22}$

Net operating margin levels and growth are key indicators of the industry's business and marketing effectiveness and appeal to investors. Net operating margin is derived by subtracting recurrent expenditure from income and expressing the result as a proportion on income. For acute and psychiatric private hospitals during 2002-2003, the net operating margin was reported to be 6 per cent, steady at the level of the previous year but above the average margin for the five years to 2002-2003 of 5 per cent. ${ }^{23}$

Relative positioning of the five competitors in the for-profit listed private hospitals can be viewed from the perspective of their size in terms of beds and their geographical coverage or proximity to primary markets prior to the 2005 mergers. Figure 3 approximates how the companies are positioned on these dimensions.

\section{Nonprofit private hospitals}

Private hospitals operated by religious or charitable institutions offer an alternative source of private hospital services to some Australian patients. Patients may elect to attend for treatment at a hospital in the nonprofit sector if convenient, practical and 
if their medical practitioner refers them. For the year 2002-2003, religious or charitable hospital groups accounted for 37 per cent of the available beds in acute and psychiatric private hospitals. Their bed occupancy rate of 77.5 per cent for 20022003 was higher than that for acute and psychiatric bed occupancy in the private hospital group overall, which was reported at 75.6 per cent for 2002-2003. ${ }^{24}$

Market shares of beds in the not-for-profit private hospitals are as follows (Department of Health and Ageing, ABS, MRE August 2003);

\begin{tabular}{|c|c|c|}
\hline Sisters of Charity & 2,586 beds & $10.4 \%$ share \\
\hline $\begin{array}{l}\text { Little Company } \\
\text { of Mary }\end{array}$ & 1,416 beds & $17.2 \%$ share \\
\hline St John of God & 1,300 beds & $15.8 \%$ share \\
\hline Mercy Health & 1,100 beds & $13.4 \%$ shat \\
\hline $\begin{array}{l}\text { Uniting Health } \\
\text { Care }\end{array}$ & 993 beds & $12.0 \%$ sha \\
\hline $\begin{array}{l}\text { Mater Health } \\
\text { Services }\end{array}$ & 830 beds & $10.1 \% \mathrm{sl}$ \\
\hline
\end{tabular}

Relative positioning of the five competitors in the not-for-profit listed private hospitals can be viewed from the perspective of their size in terms of beds and their geographical coverage or proximity to primary markets. Figure 4 approximates how the companies are positioned on these dimensions.

\section{Potential industry entrants}

The two important considerations in reviewing the topic of new entrants to the Australian Private Hospital Industry are the levels of attractiveness and the barriers to entry. Industry income form the focus of operations for this analysis (acute and psychiatric) has increased in money terms by 9 per cent per anum over the five years to 2002-2003. Removing the adjustment for price changes over the period, the figure shows a 6 per cent growth. Taking income as a key indicator of industry growth, it can be concluded that the industry would be only moderately attractive to potential entrants.

Net operating margin can be reviewed in our effort to assess the level of industry attractiveness in terms of future profitability of potential entrants. This has been discussed above and shows an average of 5 per cent

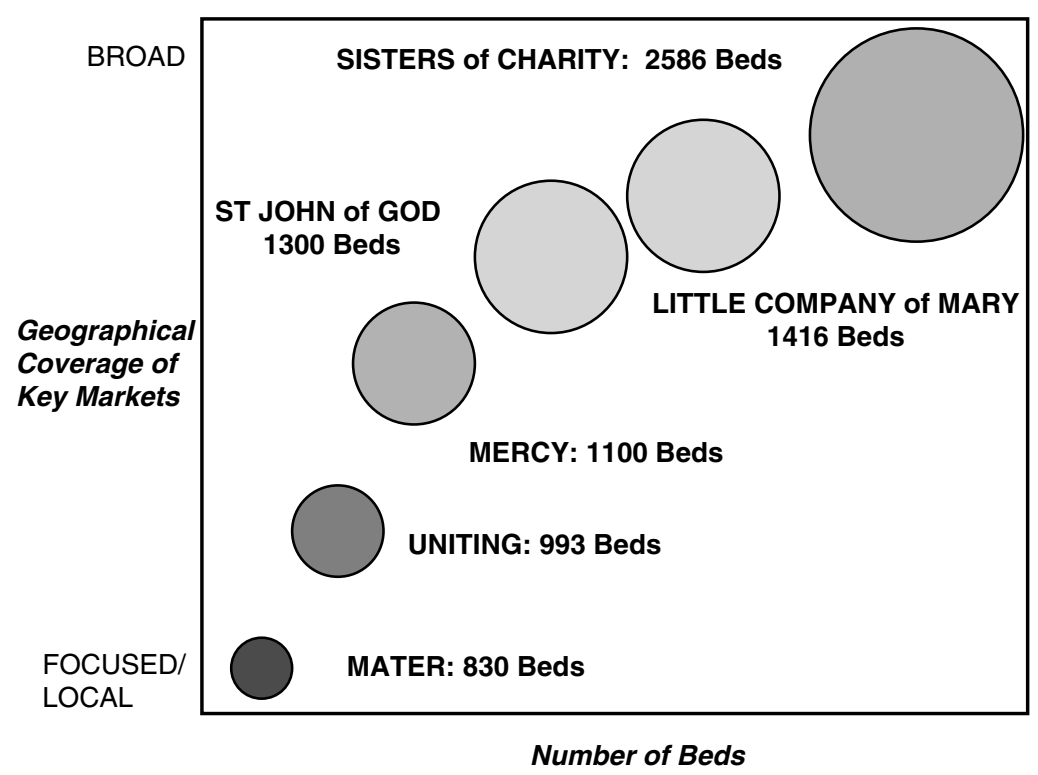

Figure 4: Relative positioning of private hospital companies; Not-for profit (psychiatric and acute care) 
for the five years to 2002-2003. In terms of profit attractiveness, it can be concluded that the level of industry attractiveness is low to moderate.

There are a number of complications that potential entrants would face in executing a strategy of establishing new Greenfield (ie building hospitals from scratch) private hospital operations in Australia. The first is the substantial capital cost involved, estimated to be in the order of $\$ 450,000$ per private hospital bed in 2004. Such high capital costs would make it difficult to achieve an acceptable level of profit margin under current operating conditions. ${ }^{25}$ The second is the long lead times necessary to find sites, purchase land, gain the various approvals and build hospital capacity strategically positioned adjacent to prime Australian markets. The third and probably the most difficult would be in recruiting and securing the optimum mix of referring medical practitioners. The fourth most critical factor would be the recruiting of nursing and hospital general staff in a market environment that is already suffering from a critical shortage. The run-on effect of this would be the tendency to push up ongoing costs for this important ingredient to the private hospital industry operating dimension.

A general conclusion from the potential new entrant dimension is that it would be relatively unattractive to enter the Australian private hospital industry by way of setting up new facilities. Hence the most likely entry strategy would be through the acquisition of an existing operation (ie Affinity, Ramsay or Benchmark), which was most closely aligned to meet the strategic objectives and fit of the acquiring organisation. This could be a large offshore company looking to diversify geographically and/or in terms of product and case mix.

An extension to the discussion of potential entrants is the feasibility of one of the three main existing companies leaving the industry. As the assets of each company are specialised and therefore can only be applied to the business of private hospital operations, assets could not be readily applied to another business or industry on a similar scale. Hence the likelihood of industry exit would be by way of selling the whole business or individual hospital combinations to existing competitors or new industry entrants.

\section{Substitute products and services}

An industry analysis should include a discussion on the impact of substitutes or alternatives to the products and services offered by industry members. This discussion should be broad enough to include possible future events that could impact the nature and/or level of demand; for example, technological change introduced by nonindustry entities, legislative/ regulative changes, industry boundary changes, new products and services offered by others not in the industry. Doing without products and services can also be thought of as a substitute as it also impacts the demand for products and services of the industry.

The impact of substitution has the potential of effecting not only the levels of demand and industry growth rates but also other critical variables such as average price yields and profitability. It is useful to think of the potential level of impact of substitution on industry demand in terms of being Low, Moderate or High.

A brief review for each of the potential substitution impact areas is listed below.

\section{Public hospitals}

Patients may elect to attend a public hospital for treatment. This is providing that they can gain admittance as there is a general shortage of public hospital beds in Australia. In an effort to contain demand for public beds, a comprehensive waiting list is maintained for many medical conditions considered to be noncritical. Competition or substitution effect from public hospitals is 
limited as their patients usually carry private health insurance. During 2002-2003, 81 per cent of admitted patient separations from private acute and psychiatric hospitals carried hospital insurance. It has been suggested that some public hospitals aggressively compete for private patients, some even setting revenue targets for private patient income. ${ }^{26}$

'Substitution impact: Low to Moderate depending upon the socio economic profile of patient market catchment areas'.

\section{Day care hospitals}

Certain medical procedures carried out in private acute hospitals could be performed satisfactorily in what is separately classified as free-standing or day hospitals.

Technological advances and improvements in medical procedures would also suggest that there is a trend towards more procedures to be conducted in these facilities rather than in hospitals where overnight accommodation is required. Indeed there has been a growth rate in private day beds of 8 per cent in 2002-2003. This compares to the 1 per cent decline in bed numbers in private acute and psychiatric hospitals for 2002-2003.

Patient separations in day hospitals showed an average annual growth rate of 12 per cent for the five years to 2002-2003. This is twice the growth rate experienced in private acute and psychiatric hospitals of 6 per cent for the same period. The higher growth rate for day care separations was reflected in a 16 per cent average annual increase in income for the same period. This compares to the figure of 9 per cent experienced for acute and psychiatric hospitals. ${ }^{27}$ It should be noted that some private and acute hospitals have moved to take advantage of the growth in day surgery by converting a proportion of their facilities to day care type of operations.

'Substitution impact; Moderate'.

\section{Technology impact}

Theoretically, it is possible that breakthrough technologies could be developed and implemented by others outside the industry, which eliminate or reduce the need for medical diagnostics or procedures presently carried out in private hospitals. Such a development could have the effect of reducing patient day yields, occupancy rates and impact future revenue streams of industry members. Industry members should monitor developments so that they are aware of evolving or emerging technologies, which could impact on existing operations and thus consider timely neutralising or embracing strategies.

e-health has received considerable debate in recent times. The topic relates to the delivery of health services by electronic channels, predominately by the internet. It has the potential to impact on how certain health services are offered and delivered. If these services were aggressively marketed by interests outside the private hospital industry, this could have an impact on demand. One report suggested that the dynamics of healthcare would change dramatically because of the internet. At that stage there was, however, no evidence of a viable business model to justify aggressive marketing of e-health services even though consumers expressed interest in using a website operated by their physician. ${ }^{28}$ The benefits of e-health extend beyond the practitioner-patient connection to other parts of the supply chain by way of improved cost-effectives services to key stakeholders. ${ }^{29}$ Some researchers believe that there is considerable scope for cost health operational efficiencies on the supply chain side of the equation. ${ }^{30}$ In Australia there has been considerable leading edge foundation work done such as HealthConnect to facilitate the progressive introduction of e-health. Support and encouragement from government has, 
however, been seen as slow and less than satisfactory. ${ }^{31}$

'Substitution impact; Level of impact is unpredictable and specific to a particular technology. Hence the level of substitution from this source should be classed as low at this point in time'.

\section{Reduction in need/demand for health services}

In certain societies, there could be a reduction in the demand for the type of services now offered by private hospitals. This could take the form of improved preventive treatments or measures to the development of existing medical conditions which now require treatment. The adoption of genetic engineering practices could be one such event. Trends in population characteristics that reduce or eliminate certain medical conditions could be another possibility. Given the predictions of an increase in the median age of Australians from its current 35 years to 40 years by 2016 as mentioned in the introduction to this paper, it is most likely that there will be a substantial increase in demand for the types of services offered by the private hospital industry in the years ahead. Under this scenario, there would be no substitution effect.

'Substitution impact; Nil'.

\section{Power of suppliers}

Industry members usually rely on a network of suppliers for component ingredients to their business processes and the final products they offer customers. Suppliers can have considerable impact on the economics and dynamics of an industry. Supplies can range from finance and capital equipment through consumables to staffing. Control of supply of essential ingredients will have strategic implications for industry members. Suppliers also form part of an industry member's strategic capability. Hence the attraction of developing strategic alliances with certain suppliers in order to ensure favourable terms and continuity in supply of critical components.

Lack of competition for alternative supply sources could mean that supply conditions and costs are dictated to suit the interests of the supplier, which may not always be in the interests of industry members. Hence cost structures and operational flexibility could be negatively affected. Key variables in the supplier equation are: ${ }^{32}$

- levels of concentration within each supply group;

- ability to switch supply source or substitute type of ingredient;

- brand power of supplier, if strong can reduce the ability to seek alternatives;

- threat of forward integration by suppliers;

- supplier's customers not considered to be critical to the supplier's business viability.

Probably the most critical supplier to the private hospital industry is the medical profession by way of doctors referring patients for hospital treatment. They may be general practitioners or specialists located externally or within a hospital facility by way of leasing rooms. Having a dependable network of patient referrers is critical to a hospitals operation and viability.

Negotiations with doctors are seen as an ongoing and critical aspect of business strategy both at the company level and also at the individual hospital level. The ability to maintain strong strategic alliances with key medical practitioners is seen to be the secret for long-term success in this industry. ${ }^{33}$

Trained nurses are also a key aspect of a hospitals operation, supplying skilled care for patients. Nurse lobby groups have been strong in recent years and successful in gaining progressive wage increases and improved conditions. Hence each hospital group's viability is impacted by nurse costs and continuity of availability. Some state governments have given strong support to 
increasing the supply of nurses in an effort to breach the shortfall in qualified nurses. ${ }^{34}$

Other supply groups to the industry are those companies that supply medical equipment and consumables for private hospital operations. These represent a substantial cost component of a private hospital operation. In recent times, medical technology has become more sophisticated and tends to change more frequently. Hence this element of health service provision is of concern to those responsible for operational viability. In Australia, companies supplying medical equipment and supplies can generally be classified as oligopolies where there are a small number of organisations holding a majority market share. This structure would suggest that competitive pressures on suppliers would be limited. Hence private hospital members would not experience the benefits that may be expected in a more competitive supply environment.

\section{Power of buyers}

As in the case of suppliers to an industry, the concentration of buyers can have an impact on the dynamics and economics of an industry. If there are concentrations of buyers having the power to dictate purchase conditions and price, then profit margins may be affected as buyer groups exert that power to the interests of the buying group but at a cost to an industry member that supplies them. Here customer's loyalty continuity becomes a key strategic issue for industry members to manage.

The overall impact on that business will depend on the percentage of total sales volume that is accounted for by each buying group together with the level of power they exert at a particular point in time. Buyers' power will also be affected by the availability of alternative supply sources. Hence the number of industry members that have the motivation and capability to satisfy particular buying groups will also impact the bargaining power of buyer groups. Multiple industry members that can satisfy a buyer's needs represent alternative supply sources for that particular buyer. Hence buyer power can be exerted in buying negotiations.

In the case of the private hospital industry, it is necessary to distinguish between buyers and consumers.

Consumers are the patients who use the services offered. Buyers are the medical practitioners who refer patients to a particular hospital for treatment. In this regard the consumer plays a minor role in the buying decision process regarding the type of service to be consumed and also regarding the particular hospital where the service will be administered. In this instance, buyer power is exercised through referring doctors.

Another important dimension when observing consumer behaviour in the private hospital industry is the fact that 81 per cent of patient separations in acute and psychiatric hospitals in 2002-2003 carried hospital insurance. This was an increase of 1 per cent in 2001-2002 and a further increase from the low of 73 per cent recorded in 1998-1999. ${ }^{35}$ The Federal Government introduced a 30 per cent rebate on health insurance premiums in 1999. This resulted in an increase in private health insurance membership from 30 per cent of the population to its present 43.3 per cent, notwithstanding a 7 and 7.5 per cent increase in premiums for 2002 and 2003, respectively. ${ }^{36}$

Private health insurance is available from about 40 separate funds. There is, however, a high concentration in this industry with only two funds accounting for the majority of membership in each state (Medibank Private and MBF). ${ }^{37}$ Hence the private health insurance funds play an influential role in the price paid to hospitals for medial services provided to their members. It has been suggested that 
private health insurers are influential but still not an intelligent purchaser as payments to hospitals are not based on quality, safety or outcome. ${ }^{38}$

\section{INDUSTRY ATTRACTIVENESS OVERVIEW}

This section will briefly summarise the circumstances of each of the five industry elements or forces and make a summary assessment in terms of each areas relative attractiveness $\odot$, or unattractiveness $\odot$, to industry members.

\section{Industry core}

Through progressive rationalisation and consolidation, the for-profit sector of the industry theoretically operates as an oligopoly with three main companies owning 92 per cent of the market in private hospital beds. In the not-for-profit sector there are only four main groups operating in the industry. Under such a market structure one would expect to see intense rivalry manifest in terms of aggressive marketing activity in order to maintain or build market shares.

In the case of the private hospital industry, however, each company and hospital has its unique positioning near key markets and referring doctor networks. This unique positioning limits the competitive rivalry between the companies in the industry. It also has the effect of containing the level of marketing spend and minimising the necessity to reduce health service prices in order to attract customers.

The negative effect of limited competitive rivalry also means that it would be more difficult for an individual company to build market share through aggressive marketing similar to what could happen in most other industries when markets are not as protected. This limit on the level of competitive rivalry also has longer term benefits to shareholders of the three key companies. They benefit from better profit margins and logically larger dividend distributions over time.
It means also that yields on the asset of private hospital beds is somewhat protected from the ravages of competitive business and marketing strategies.

It should be mentioned that even though competition within this industry may be at moderate levels, conditional competition for certain patient revenue still occurs from operators outside the industry such as day care hospitals, public hospitals and the notfor-profit sector.

Another favourable dimension is the outlook for industry growth. Owing to the ageing Australian population outlined in this paper and the increasing awareness of the need for high-quality healthcare, the demand for health services is likely to continue to grow in the foreseeable future. Hence the return to shareholders of companies in the private, for-profit industry should be maintained provided costs are contained and market shares are not lost to competing industries such as the not for profit or day care.

The search for growth may involve varying degrees of diversification, whether it be into closely associated health services not currently being offered by the private hospital sector or moving into the closely associated industry of aged care. Alternatively, for those who are more adventurous, diversifying into the emerging wellness industry.

One author has identified the birth of a new and substantial industry, which runs separate but parallel to traditional healthcare industries such as the one under review. ${ }^{39} \mathrm{He}$ sees the beginning of a huge industry described as the 'Wellness Industry'. While he sees existing healthcare as reactive, the wellness industry will be proactive and dedicated to preventing people from becoming customers of the healthcare industries. Depending upon how healthcare industry members define their business, wellness could mean a whole new wave of growth opportunities for stakeholders. 
In summary, it can be stated that the competitive environment for private hospital members is generally favourable $\odot$.

\section{Entrants}

There are moderately high barriers to entry in this industry. High capital costs and the difficulty in finding and building new hospitals in locations close to viable markets present a formidable hurdle for potential new entrants to the industry. It has been suggested that the current capital costs of building and commissioning a hospital bed are about $\$ 450,000 .^{40}$ There is also the issue of obtaining the necessary bed licences in sufficient numbers from government authorities. In addition, the challenge of creating a network of effective referring doctors would take time and effort, and also increase the cost of entry.

Entry on a relatively large scale could take place through acquisition. Such an entrant could be a company with substantial funds to invest in diversified geographical markets. An example here may be a large US healthcare company. Another example may be a health insurance company wanting to integrate forward from insurance to health service provision. Industry entry under these circumstances cannot be classified as a negative threat to shareholders as it could be assumed that such an entrant would need to pay a premium to encourage shareholders of the target organisation to sell controlling interest in a private healthcare company.

Following this rationale, it can be said that the threat of new entrants impacting on industry players in a negative or damaging way to shareholder assets and returns is low $\odot$.

\section{Substitutes}

Taking the definition of substitutes as alternative health services offered by organisations outside the core industry, the following summarises each element that was discussed above in the main text under 'Substitute Products and

Services':

- Not-for-Profit hospitals: Medium to High threat depending on hospital location.

- Public Hospitals: Low to Medium threat depending on the location and market demand.

- Day Care hospitals: Medium threat depending on the type of service and location.

- Technology as a Substitute to private hospital care (eg e-health): Low threat.

- Reduction in need/demand for private health services: Nil threat.

Following this rationale, it can be summarised that the combined threat of substitutes impacting on industry players in a negative or damaging way to shareholder interests or assets and returns is low. Hence this element is favourable to industry members $\odot$.

\section{Suppliers}

This variable has the potential to be the most critical for members of the for-profit private hospital industry in managing viable hospital units. Individual organisations rely on key groups to supply quality and timely services and products to the various hospital locations. Each of the main supplier components are summarised as follows.

\section{Medical practitioners}

Having a strong network of referring doctors is a fundamental prerequisite to viability and success. They also need to be positively supportive of each hospital and company. Case histories show that nonsupport of doctor groups can lead to serious underperformance of both individual hospitals and company groups in this industry. ${ }^{40}$

\section{Nursing staff}

Also a critical component of the private hospital operation. In Australia they are well 
organised in terms of union representation and enjoy a strong positive image with the press and the public. Nurses therefore have strong collective bargaining power with private hospital groups. Hence they are in a strong position to negotiate conditions and pay structures.

\section{Consumable medical supplies}

Most consumables used in private hospitals are supplied by industries that are oligopolies in structure. Hence individual supplying companies can usually exercise some control over price and supply conditions. Protheses are a costly component of some medical treatments and are supplied by a limited number of suitable manufacturers. It has been said that supplying manufacturers are specified by medical practitioners in $20-40$ per cent of cases that require the use of a prothesis. $^{40}$

\section{Medical equipment}

Over time, the private health industry has become increasingly dependent on advancing technology by way of high capital cost equipment used for diagnostics and treatment of medical conditions. There are a limited number of companies supplying such equipment. Hence there is limited opportunity for competitive buying by hospitals. Rapidly advancing technologies, which are an integral aspect of equipment, also infer that purchase prices for such equipment will be relatively high. This is due to the need to recuperate research and development costs and the lack of direct competition in each equipment category.

In summarising the impact of the suppliers, it can be said that they have the potential to impact industry players in a negative or damaging way. Even if this influence is not activated, they hold a latent power that can be used in negotiating conditions of supply to industry members $\odot$.

\section{Buyers}

The role of buyer in this industry structure is complicated by the fact that private hospital patients rely heavily on two key groups that have a powerful role to play in the specification, supply and payment of the health services provided.

The first group is the referring doctors that specify and recommend not only the procedure to be followed but also the location or hospital where the procedure will be administered. As most private patient separations (81 per cent in 2002-2003) ${ }^{41}$ carry private health insurance, the health insurance funds play a key role in deciding how much will be paid to a hospital for a particular service and how much gap the patient will need to pay for the service. The roles that each of these two key groups play have been discussed under the appropriate categories above. Australian private hospitals rely heavily on the health insurance funds for the payment of its services. In 2004, they paid for 77 per cent of available bed days. ${ }^{42}$

In summarising the role of patients in isolation to other influencing factors, it can be said that their ability to impact industry players in a negative or damaging way to shareholder interests or assets and returns is low. Hence this element is favourable to industry members $\odot$.

\section{Overview}

Figure 5 summarises the status of the private hospital industry in terms of unfavourable and favourable influences impacting its operations.

Analysis of this industry shows that overall it is a favourable operating environment for industry members, with four assessments being summarised as favourable and only one as being potentially unfavourable. The unfavourable rating was allocated to the supplier sector because of the potential impact of the use of power by the various suppliers to industry members. Here suppliers could dictate both terms and 


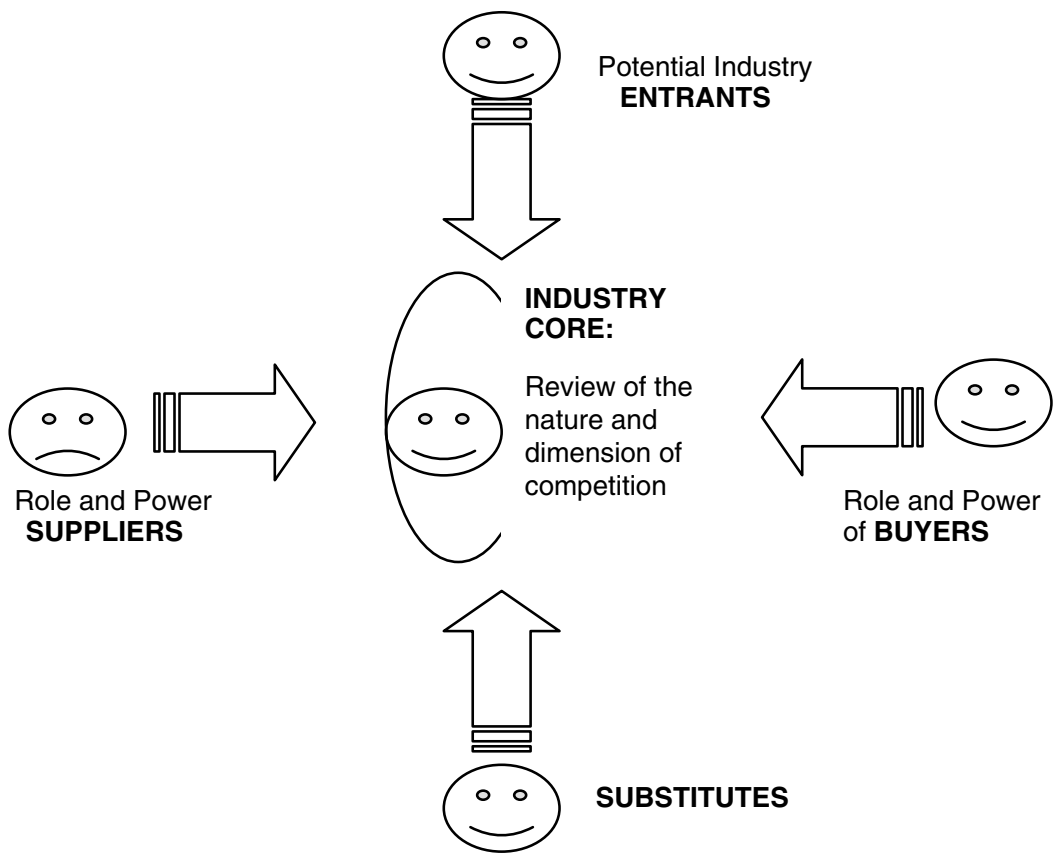

Figure 5: Industry attractiveness summary

cost of supply, thus impacting industry member viability. This negative impact effect has been sighted as an important reason for the poor performance of the previous Mayne group. ${ }^{43}$ Indeed, long-term favourable supply relationships for industry members have been seen to be a prerequisite for long viability of private hospital industry members. ${ }^{43}$

\section{KEY OBSERVATIONS}

Some key summary observations from this analysis are as follows:

- Growth levels for acute and psychiatric patient separations over the most recent five years have been modest at 6 per cent per annum.

- With the projected ageing population, there will be a continued high level of awareness and need for private health services by Australians.

- In 2002-2003, four out of ten patients admitted to hospital were admitted to private hospitals. This has been part of a continuing trend toward the use of private hospitals. In 1992-1993 this percentage of private to total was 18 per cent.

- Key changes to industry structure and numbers have occurred mainly in the for-profit sector of the industry. Consolidation in this sector leaves two listed companies (Ramsay and Healthscope) with 48 per cent of the total private hospitals beds in acute and psychiatric care.

- Each private hospital group or company tends to have unique positioning near key markets and referring doctor networks. This unique positioning limits the competitive rivalry between the companies in the industry. It also has the effect of containing the level of marketing spend and minimising the necessity to reduce health service prices in order to attract customers.

\section{IMPLICATIONS FOR MANAGERS}

Following from this analysis, what are the implications for managers in the private hospital industry? What are the implications 
in terms of optimum management knowledge, skills and processes?

A major and constant focus on profit margin management. There are strong pressures from the health insurance funds to contain prices charged for hospital services. There are also very strong pressures on the private hospital cost dimension by the key supplier groups of products and services to the industry, namely medical practitioners, nursing staff and medical equipment suppliers. Hence a critical and ongoing management skill is to run hospital operations to acceptable quality standards with less-costly resources and with constant operational innovation. Another dimension of margin management is to actively manage case mix by increasing the proportion of services with higher profit margins.

Strategic management skills will become more critical as pressure builds to find future revenue and growth opportunities. These opportunities will come through varying combinations of the successful introduction of new products and services, increased penetration to high-priority market segments or accessing new markets not currently being served. These opportunities may be in areas closely related to the existing business definition such as diagnostics, post-treatment services, enhanced in-hospital services etc. They could also include opportunities more diverse from the traditional private hospital business such as aged care, preventive healthcare, 'wellness' and disease-prevention services

The ability to make strategic change a reality will depend on applied marketing skills. As strategic priorities are established, detailed marketing objectives and strategies need to be formulated and implemented with cost accountability and key performance indicators used for tracking and monitoring progress.

Given the power distribution of key stakeholders in the industry, a key ongoing management skill and process will be the effective management of relationships with key supplier groups such as the medical practitioners, health insurance funds and equipment suppliers. Ongoing and proactive relationship planning and actions will be fundamental here so that issues are resolved in a timely and cost-effective manner and to ensure that crisis or ad hoc solutions are avoided as much as possible.

\section{FUTURE ISSUES}

Likely future developments that will impact industry members and their performance are likely to be:

- Changing government health policy and strategy both at the Federal and State level.

- Further industry consolidation as individual companies attempt to achieve growth targets, gain effective market coverage, reduce market area competition and gain from the benefits of economies of scale (eg operating efficiencies, bargaining power with suppliers and health funds).

- A squeeze on profit margins. On one hand will be rising costs associated with conducting hospital business in areas such as nursing staff, medical supplies and equipment, and new technologies. On the other hand will be pressures on revenue levels because of health insurance fund payments to private hospitals, resistance of patients to pay increasing out-of-pocket gaps, and pressures by medical practitioners to increase fees.

- Doctors and nurses are seen to continue to play a critical role in all private hospital operations. Hospital viability depends upon their positive support and involvement. Cost and supply continuity is also an ongoing and critical dimension for each hospital to manage effectively. Strategic thinking at the industry level on this important 
issue has even considered such strategies as the introduction of a hybrid doctornurse to ease pressure in critical rural regions of Australia. ${ }^{44}$

- Increasing attempts for industry members to diversify from the traditional core business in their attempts to achieve growth targets, diversify risk, and build profit margins and return on investment.

- The role of private health funds also presents important issues for the industry and its stakeholders. Their ongoing viability will rely on maintaining the 30 per cent government rebate regardless of the political party in office. There is also the issue of membership profile where younger, healthier members participate. In the balance is the way in which private hospitals negotiate and are paid for services provided to members.

- There have been suggestions that information technology initiatives taking place in hospitals have the potential to transform the industry and the way it operates. Integrated systems can provide substantial improvements to the quality and flow of information between patient, hospital and physician. ${ }^{45}$

\section{References}

1 Johnson, G., Scholes, K. and Whittington, R. (2005) 'Exploring corporate strategy', Prentice-Hall, Harlow, England.

2 Hubbard, G. (2004) 'Strategic management', Pearson Education Australia, Frenchs Forest.

3 Macquarie Research Equities (MRE) (2003a) 'Ramsay health care report', July.

4 Interview with Barry Catchlove, Industry Consultant.

5 Foley, M. (2000) 'The changing private-public balance' in: Bloom, A.L. (ed.) 'Health reform in Australia and New Zealand', Oxford University Press, South Melbourne, pp. 99-114.

6 Australian Bureau of Statistics (ABS) (2006) '4390.0, Private Hospitals, Australia', Australian Bureau of Statistics (ABS), Canberra.

7 Johnston, R. B. and Gregor, S. (2000) 'A theory of industry-level activity for understanding the adoption of interorganisational systems', European
Journal of Information Systems, Vol. 9, No. 4, pp. 242-251.

8 Productivity Commission (1999) 'Private hospitals in Australia', Commission Research Paper, AUSINFO, Canberra.

9 Moriarty, C. (2004) 'Ramsay health defies the odds', The Sunday Telegraph, 15 June.

10 Macquarie Research Equities (MRE) (2003b) 'Ramsay health care/healthscope; Small competitors to feel the margin squeeze', 6 August.

11 Quints, T. and Marks, N. (1997) 'Health Care and insurance in Australia 1997', Volume 1, TQA Research P/L, Melbourne.

12 Productivity Commission (1999) op cit.

13 Porter, M. E. (1980) 'Competitive strategy: Techniques for analysing industries and competitors', Free Press, New York.

14 Rumelt, R. P., Schendel, D. and Teece, D. J. (1991) 'Strategic management and economics', Strategic Management Journal, Vol. 12, pp. 5-29.

15 Hoskisson, R. E., Hitt, M. A., Wan, W. P. and Yiu, D. (1999) 'Theory and research in strategic management: Swings of a pendulum', Journal of Management, Vol. 25, No. 3, pp. 417-456.

16 Macquarie Research Equities (MRE) (2003a) op cit.

17 Ramsay Health Care Limited (2005) Prospectus for 1 for 9 Offer of New Shares, April 19, ABN 001 288768.

18 Productivity Commission (1999) op cit.

19 Interview with Patrick Grier, CEO, Ramsay Health Care.

20 Johnson, G., Scholes, K. and Whittington, R. (2005) op cit.

21 Australian Bureau of Statistics (ABS) 2004 '4390.0, Private Hospitals, Australia', Australian Bureau of Statistics (ABS), Canberra.

22 Ibid.

23 Ibid.

24 Australian Bureau of Statistics (ABS) (2004) op cit.

25 See ref. 19 above.

26 See ref. 4 above.

27 Australian Bureau of Statistics (ABS) (2004) op cit.

28 Goldbrick, C. (2000) 'The road to e-health: Marketing implications', Marketing Health Services, Vol. 20, No. 4, pp. 32-35.

29 Moore, E. and McGrath, M. (2002) 'An Australian case in e-health communication and change', The Journal of Management Development, Vol. 21, No. 7/8, pp. 621-633.

30 Kim, S. M. (2004) 'An empirical investigation of the impact of electronic commerce on supply chain management: A study in the healthcare industry', $\mathrm{PhD}$ dissertation, The University of Nebraska, Lincoln, 132pp.

31 Dearne, K. (2006) 'Howard backing away on e-health', IT today, The Australian, Tuesday, 24 January.

32 Johnson, G., Scholes, K. and Whittington, R. (2005) 'Exploring corporate strategy', Prentice-Hall, Harlow, England.

33 Greenblat, E. (2004) 'Ref in the private hospital scrum', Australian Financial Review, 28 May. 
34 Wood, M. (2004) 'We'll search world to recruit nurses', The Sun Herald, 14 November.

35 Australian Bureau of Statistics (ABS) (2004) op cit.

36 Australian Private Hospitals Association (2004) 'Private Hospital Information', Private Health Industry Discussion Group, April.

37 Citigroup: Smith Barney (2005) 'Medicare Handbook 2005, An Analysis of The Australian Healthcare Sector', 4 April.

38 See ref. 4 above.

39 Pilzer, P. Z. (2002) 'The wellness revolution', John Wiley and Sons Inc, New York.
40 See ref. 19 above.

41 Australian Bureau of Statistics (ABS) (2004) op cit.

42 Deutsche Bank (2005) 'Private hospital operators: Consolidation remains the key to earnings growth', 19 July.

43 Macquarie Research Equities (MRE) (2003a) op cit.

44 Cresswell, A. (2005) 'Radical plan for doctor-nurse hybrid', The Weekend Australian, 23-24 July.

45 Mullaney, T. and Weintraub, A. (2005) 'The digital hospital', Business Week, 28 March. 